\title{
Audit of fidelity of implementation of the older prisoner health and social care assessment and plan (OHSCAP)
}

\author{
Katrina Forsyth ${ }^{a}$, Nicola Swinson (iD ${ }^{b}$, Laura Archer-Power ${ }^{a}$ Jane Senior (iD ${ }^{a}$, \\ Daisy Shaw ${ }^{c}$ and Jenny Shaw ${ }^{\mathrm{a}, \mathrm{c}, \mathrm{d}}$
}

a Offender Health Research Network, University of Manchester, Manchester, UK; ${ }^{b} S c h o o l ~ o f$ Psychological Sciences and Health, University of Strathclyde, Glasgow, UK; 'Medical Student, University of Manchester, Manchester, UK; ${ }^{\mathrm{d}}$ Greater Manchester West NHS Foundation Trust, Manchester, UK

\begin{abstract}
Numbers of older prisoners have been increasing in recent years and there is no national strategy addressing their care. Older prisoners have more physical health needs, complex social care needs and high rates of mental disorder compared with younger prisoners. These needs are often not identified or addressed. We developed the Older prisoner Health and Social Care Assessment and Plan (OHSCAP), a structured approach for identifying and managing the health and social care needs of older prisoners. It consists of an assessment, care plan and review of needs. The current study aims to establish the fidelity of implementation of the OHSCAP as part of a larger RCT. Compliance, context and competence fidelity were audited to assess compliance with training and the manual, adequacy of completion and identification of needs and quality of care planning. Results showed that the OHSCAP was not implemented as intended with needs identified not being consistently translated into care plan actions, little evidence to suggest that prisoner involvement in the care planning process and difficulties in collaborative working. Implications with respect to effectively embedding complex interventions within prisons, along with wider policy-related issues affecting the entire prison estate are discussed.
\end{abstract}

ARTICLE HISTORY Received 13 September 2019; Accepted 7 January 2021

KEYWORDS Older prisoners; health and social care; needs assessment

\section{Introduction}

In recent years, numbers of older prisoners have been increasing, both within the UK (Ministry of Justice, 2014), and across developed countries worldwide (American Civil Liberties Union, 2012; Ministry of Justice, 2004). Older prisoners are most frequently defined as those aged 50 and over; evidence suggests 
equivalence in health problems in this group to those over 60 years living in the community (Wahidin, 2005). Within England and Wales, those aged 50 and over account for $16 \%$ of the prison population and the proportion continues to rise; data show 13,559 in this age group in prison in England and Wales (Ministry of Justice, 2016a).

Reasons for this increase are multifactorial and include an ageing population, an increase in crimes committed by older people (Howse, 2003) and changing sentencing practices with more older people receiving longer sentences (Frazer, 2003) including for historical offences.

Despite repeated calls (Ginn, 2012; Hayes et al., 2013, 1999), there is no national strategy for the care of older prisoners and Her Majesty's Chief Inspector in Prisons review (HMCIP, 2016) found that many standards outlined in the National Service Framework for Older People [Department of 12] applicable to this group were not being met.

Older prisoners have a higher rate of physical health problems (Hayes et al., 2012; Kingston et al., 2011; Senior et al., 2013) than both younger prisoners (Bridgewood \& Malbon, 1995) and those aged over 65 years in the community (Prior, 1998). There is very little evidence, however, on the extent to which these needs are addressed. Similarly, they have high rates of mental disorder, with prevalence rates ranging from $50 \%$ to 61\% (AmericanCivilLiberties Union, 2012; Fazel et al., 2001; Kingston et al., 2011). The most common reported diagnosis is depression, with concerningly high rates of severe depression in newly received prisoners (Senior, 2013). Less than one in five of those with symptoms of depression are prescribed antidepressants (Fazel et al., 2004; Senior et al., 2013). Older prisoners also have complex social care needs, with unmet needs in relation to activities of daily living (ADLs) (Hayes et al., 2012) including prison activities of daily living (PADLs) as a result of mobility problems and sensory impairment (Williams et al., 2006). Following release, a lack of appropriate and timely support with housing has been identified (Hayes et al., 2013) compounded by problems with planning health care and financial issues (Senior et al., 2013).

On reception into prison, there is a mandatory health screen which aims to identify immediate health concerns (Grubin et al., 1999). A second, more detailed, mental health assessment is recommended but frequently does not take place (Shaw et al., 2009). Moreover, social care needs are not comprehensively assessed as part of this standardised assessment. There is no specific standardised assessment for older prisoners; some institutions have developed their own although evidence suggests delivery is sporadic (Senior et al., 2013).

Older prisoners receive the same treatment as their younger counterparts with little consideration of their differing needs related to ageing. For example, they may be given insufficient times to move between different locations 
or complete activities, being allocated top bunks when they have mobility issues and being unable to access exercise owing to the lack of provision of seating or accessible toilets in the exercise yard (Crawley, 2005).

The HMCIP review identified serious concerns that the needs of older prisoners after release were not planned or provided for, and only four prisons in England and Wales provide specific resettlement support (HM Inspectorate of Prisons, 2008). Increased health and mobility problems alongside poorer support networks result in significant levels of anxiety among older prisoners regarding release (Davies, 2011).

Given the ad hoc management of the needs of older prisoners, we developed the Older prisoner Health and Social Care Assessment and Plan (OHSCAP) using action research with prison staff, health-care staff, and prisoners in one establishment in England. OHSCAP is a structured approach for identifying and managing the health and social care needs of older prisoners. It consists of an assessment, care plan, and review of these needs. It was found to be both feasible and acceptable to prisoners, as well as being effective at reducing older prisoners' unmet health and social care needs during a pilot study (Senior et al., 2013).

The OHSCAP is a paper-based assessment, which is uploaded onto existing prison, health, and offender management computer programmes. The assessment comprises open questions on three areas: social (relationships, activities, and mobility); well-being (emotional and physical well-being, medication and treatment); and discharge planning. The care plan identifies issues, actions, and review and the review section outlines progress and actions with dates for the next review. The assessment occurs 7-14 days after reception and is carried out by the older prisoner lead (prison officer or health-care worker) in collaboration with the prisoner, who retains a copy of the care-plan.

The current study was part of a large scale randomised controlled trial of OHSCAP across England evaluating the effectiveness and cost-effectiveness of OHSCAP, along with the experiences of both staff and prisoners in utilising it. A total of 497 prisoners were recruited to the trial (248 to OHSCAP and 249 to Treatment as usual (TAU)). No significant differences were observed between the intervention and TAU groups in relation to mean number of unmet health and social care needs as measured by the Camberwell Assessment of Need - Short Forensic Version. There were no significant differences in relation to costs (Forsyth, 2017).

Successful implementation of interventions, both as part of research studies and in clinical practice, is a complex process and reasons for interventions not being implemented as intended are multifactorial. One of the critical issues is engagement of practitioners with the proposed changes, including contribution at the development level (Pearson et al., 2015). Difficulties in implementation in the RCT compared with the pilot study 
may reflect a greater level of engagement of participants within the pilot study, given their involvement in developing the assessment. It is important to ascertain whether the negative outcome of the RCT reflects difficulties in the process of implementation, or with the OHSCAP itself.

The aims of this particular study were to establish the fidelity of implementation and assess the quality of care plans produced through OHSCAP as part of the RCT.

\section{Methods}

A multicentre, parallel-group randomised controlled trial (RCT) of four hundred and ninety-seven newly arrived male prisoners aged $\geq 50$ years with a discharge date at least 3 months from recruitment was conducted across 10 English prisons. They were randomised to OHSCAP or TAU (Treatment as usual) with follow-up at 3 months.

Subsequent to the completion of all OHSCAP assessments and data collection in all study sites, the OHSCAP lead at each site was contacted and anonymised photocopies of the assessments and care plans they had produced throughout the duration of the study were requested. Once collated, the anonymised copies were audited by a reviewer, trained by, and independent of, the research team.

Each OHSCAP was assessed by the reviewer using a bespoke pro forma designed to assess the quality of the assessment and care planning (see Appendix 1). $10 \%$ of the OHSCAPs audited were also audited by a researcher for the purposes of establishing inter-rater reliability. Inter-rater agreement was measured using Cohen's kappa coefficient statistic, specifically in relation to the final section of the audit tool, which required a subjective judgment about the appropriateness of care plan actions.

The audit tool comprised three core sections: compliance fidelity, context fidelity, and competence fidelity. The compliance fidelity section assessed the extent to which key elements of the process were conducted as per training and the OHSCAP manual. Elements assessed included: how many days after reception the OHSCAP was completed (target 7-14 days); whether reviews were completed according to the planned timescale; whether the care plan was copied to various electronic systems and paper records within the prison.

Context fidelity assessed the adequacy of completion of particular needs and the level of detail provided. This section also included whether or not any outstanding needs were identified in each area and, if so, whether or not a corresponding action was documented in the subsequent care plan.

Finally, the section on competence fidelity sought to assess the quality of care planning, in terms of the extent to which care plan actions were an appropriate response to the outstanding needs identified. 
Overall, 220 OHSCAPs were completed, of which 150 (68.2\%) were available for potential audit. Only one site provided $100 \%$ of completed OHSCAP assessments to the research team for audit. In most sites, between 1 and 10 OHSCAP assessments were lost, with the exception of site 2 , where an entire folder of filed assessments went missing during office moves. The prison health-care provider changed at this site and large volumes of paperwork were securely destroyed as part of the transition. Assessments were audited from 9 of the 10 study sites. One site, from which only four participants were ever recruited, was unable to provide copies of the two OHSCAP assessments that it completed.

\section{Results}

\section{Process (compliance fidelity)}

\section{Information sharing}

Almost three-quarters $(111,74 \%)$ of the OHSCAPs audited were completed by prison staff, with health-care staff completing the other 39 (26\%).

The OHSCAP training manual requires that copies of assessments and care plans are offered to the prisoner and are uploaded onto (1) the electronic clinical records system, (2) the C-NOMIS prison records system, (3) the probation service's system and (4) placed in the prisoner's core record. The audit found that facilitators recorded that they had not copied the care plan to any of the various systems in many cases, and even more rarely to the prisoner (Figure 1).

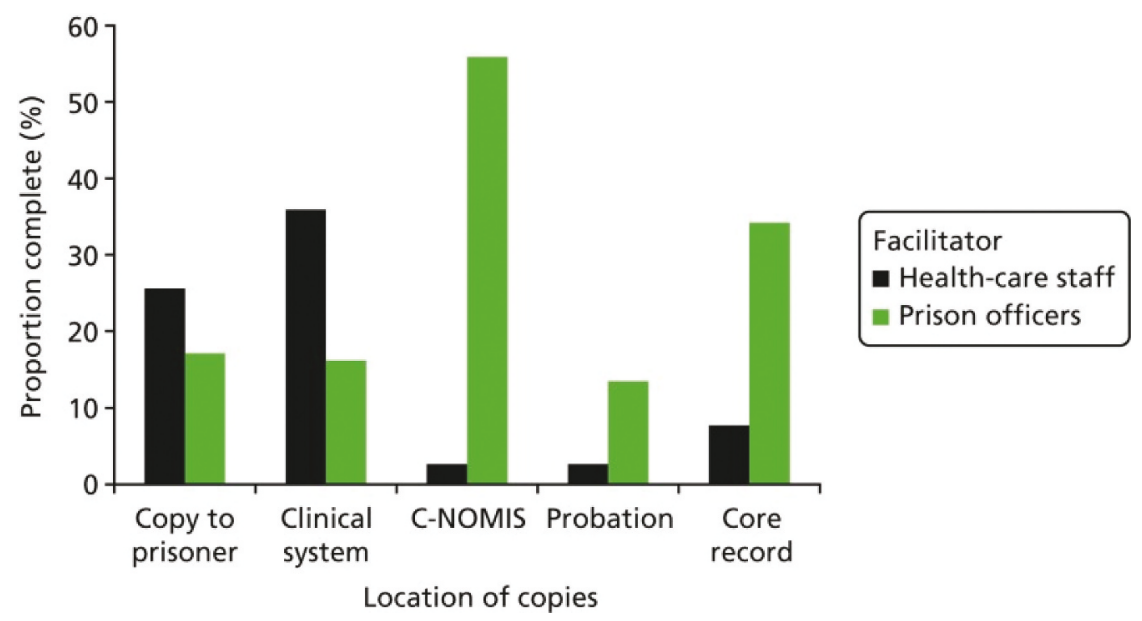

Figure 1. Copies/uploads to prisoner and systems by facilitator role. 
Reasons for this are multi-factorial. It was often noted that the prisoner was offered, but declined, a copy, perhaps for privacy reasons. Furthermore, difficulties in accessing prison and probation records by healthcare staff, meant that health-care staff copied the care plan to the clinical system in a greater proportion of cases than prison staff and vice versa for the prison staff, while there was little difference between the groups in terms of providing the prisoner with a copy (Figure 1). It is standard practice that health-care staff have access to both health-care and prison systems, while, for reasons of medical confidentiality, prison officers are not permitted access to health-care systems. Therefore, prison officers could share the OHSCAP on the electronic clinical records system only with the help of a health-care colleague.

\section{Completion of the assessment and care plan}

The OHSCAPs were completed, on average, 20 days after arrival into the prison (mean 20.43 days, median 18 days). Time from arrival to completion of the OHSCAP ranged from 4 to 63 days. The OHSCAP manual stipulates that the assessment and care planning process should be completed 7-14 days after reception.

A care plan was generated following fewer than half of the assessments audited $(65 ; 43 \%)$. Plans were completed on $46 \%$ and $43 \%$ of cases by healthcare staff and prison officers, respectively.

In the majority (69\%) of assessments that resulted in a care plan, there was no clear reference to the prisoner having been involved in the development of the care plan. The OHSCAP manual stipulates that the care plan should be completed in conjunction with the prisoner and stresses the importance of involving them in the care planning process. The lack of explicit, written evidence of the prisoners' involvement in the process, however, may reflect an issue with documenting prisoners' involvement in the care planning process, rather than failure to actually involve them in the process in practice.

\section{Reviews}

The OHSCAP manual stipulates that each individual should be offered a review at least every 6 months. The timing of review for each care plan action is left to the discretion of the OHSCAP facilitator, with the aim of allowing facilitators the flexibility to prioritise the most urgent actions, while providing additional time to deal with less-pressing issues. However, the evidence obtained from the audit process suggests that facilitators generally struggled to implement the review process as intended.

An initial review was set following 54 assessments ( $36 \%$ of the sample), but there was only evidence of this having taken place in 22 cases (15\% of all OHSCAPs audited). 
There was no evidence that any of the reviews set for $\geq 13$ weeks after the assessment took place. This could indicate that some of the facilitators forgot to conduct reviews that they had set for the maximum of 6 months post assessment.

Only six of the 22 facilitators who completed an initial review set a second review. The second review was completed in all six cases, but only two within the planned time frame.

\section{Quality and extent of completion (competence and context fidelity)}

The extent to which all questions and sub questions were addressed, and the level of detail of the information recorded, could prove important at a later stage in terms of allowing another professional to be able to pick up the assessment and understand the prisoner's needs. Most sections (relationships, activities, emotional well-being, medication and discharge planning) were most frequently assessed as being completed to a 'good' standard. However, the sections that were most likely to improve outcomes (i.e. the care plan and the review) were most frequently rated as 'not complete' (Table 1).

\section{Problem identification and response}

In total, 194 problems were identified across all areas, but only 115 (59\%) were translated into care plan actions. Proportionally, the areas least often addressed were discharge planning (35\%), emotional well-being $(41 \%)$ and mobility (52\%) (Figure 2).

Problems regarding relationships included concerns for personal safety or family members, problems using prison telephones, financial difficulties and wanting transfers between wings or prisons. Only 16 out of $26(62 \%)$ of these problems were addressed in care plans. Financial problems were the least likely to be addressed, with four out of five not translating into care plan actions. Of the 31 mobility problems identified during the OHSCAP assessments, only $16(52 \%)$ were actioned in the care plans that followed. Difficulties with getting in or out of bed were more often not addressed (64\%) than any other type of problem within this category.

Only 7 of the 17 (41\%) emotional well-being problems raised during assessment resulted in care plan actions. Difficulties sleeping were the most common type of problem reported $(n=7)$, and also the least often addressed (29\%).

With $70 \%$ of physical well-being problems identified leading to a subsequent care plan action, these were addressed more often than any other type of problem.

Most problems in discharge planning were not addressed during the OHSCAP care planning process. None of the identified financial concerns were actioned and only half of those relating to accommodation had corresponding actions in the subsequent care plan. 


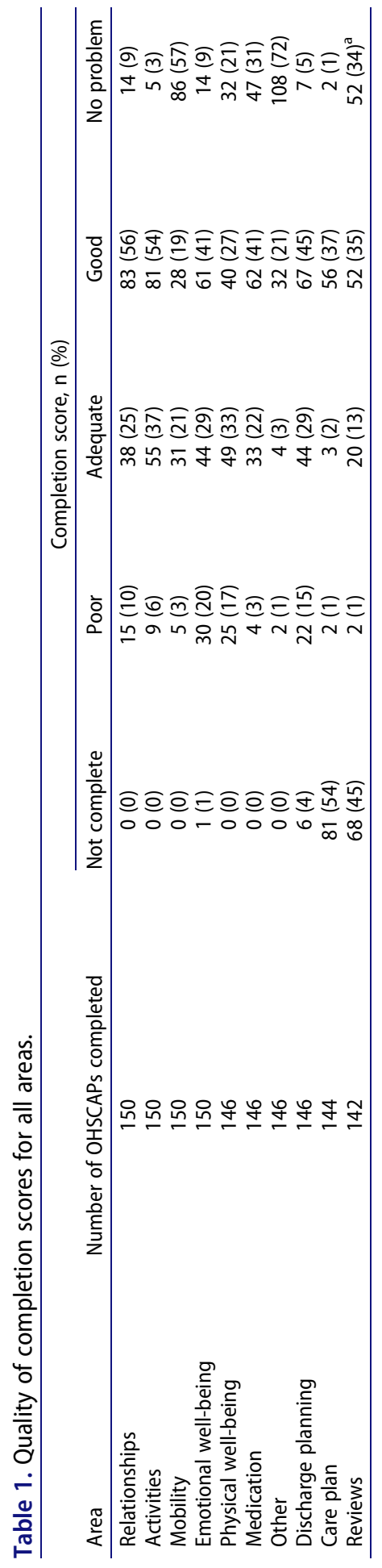




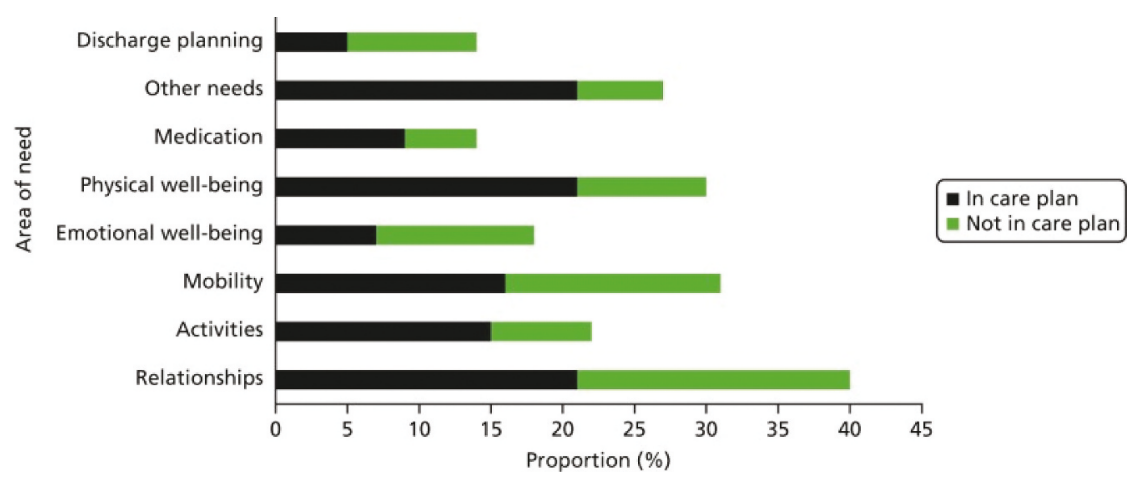

Figure 2. Translation of identified problems into care plan actions by area of need.

Notable differences can be seen according to facilitator role in terms of translating identified problems into care plan actions. Prison officer facilitators identified 157 problems in total and addressed 83 (53\%) of them during the care planning phase of the OHSCAP. Health-care staff facilitators identified only 37 problems but went on to action 32 (87\%) of them. As can be seen from Table 2, the biggest differences between facilitators were in relation to emotional and physical well-being needs, which should be easier for healthcare staff to address, given that this falls within the remit of their everyday role. Nevertheless, the reverse does not hold true in relation to prison officers and problems that could be considered more a part of their core role, with discharge planning being the area in which they least often addressed identified issues.

These data may also support the impression that there were difficulties in partnership working, as well as in sharing information across disciplines. Theoretically, regardless of who facilitates the OHSCAP process, the built-in prompts for referrals within, and outside, the prison should mean that individuals' problems are addressed by an appropriately qualified professional.

Table 2. Percentage of identified problems translated into care plan actions by area of need and according to facilitator role.

\begin{tabular}{lcc}
\hline & \multicolumn{2}{c}{ Facilitator role (\%) } \\
\cline { 2 - 3 } Category & Prison officers & Health-care staff \\
\hline Relationships & 54.1 & 33.3 \\
Mobility & 46.2 & 80.0 \\
Emotional well-being & 37.5 & 100.0 \\
Physical well-being & 57.9 & 91.0 \\
Medication & 50.0 & 83.3 \\
Discharge planning & 30.8 & $100.0^{\mathrm{a}}$ \\
Other & 71.4 & 100.0 \\
\hline
\end{tabular}

$n=1$. 


\section{Referrals}

As a result of the OHSCAPs reviewed, 36 (24\%) individuals received a total of 48 referrals; only five external referrals were made, and 43 internal referrals. Prison officer facilitators referred 23 individuals to 26 professionals. Only nine $(34.6 \%)$ of these referrals were to health-care professionals. In contrast, health-care staff facilitators made 21 referrals in total for 13 individuals, with $15(71.4 \%)$ of them being to health-care professionals.

\section{Care plan actions}

The number of needs identified within each care plan ranged from zero to six, with the mean and median being two. Almost half $(44.6 \%)$ of the OHSCAPs that resulted in a care plan only identified one need to be addressed.

Completion of the care planning section of the OHSCAP was generally poor, with one care plan action, if any, being allocated to a member of staff to complete in over $70 \%$ of the care plans generated. Furthermore, in the vast majority $(89.2 \%)$ of care plans, none of the care plan actions were timelimited, as no planned completion date was recorded.

Encouragingly, in 149 of the 150 OHSCAPs reviewed, the auditor felt that sufficient information was documented for care to be continued effectively by a professional who had not been present during the assessment interview.

\section{Inter-rater reliability}

Inter-rater agreement was fair in relation to two areas of need (activities and physical well-being) and good in four of the other areas (Table 3), applying interpretations of Cohen's kappa provided by Altman (Altman, 1991).

In the final two areas of need, Cohen's kappa could not be computed as a result of one of the raters' responses being constant across all cases. Analysis of the percentage of cases' scores on which raters agreed revealed that in relation to both areas of need, agreement was $86.7 \%$ (13 out of 15 cases).

Table 3. Inter-rater agreement on ratings of appropriateness of care plan actions.

\begin{tabular}{|c|c|c|c|}
\hline Area of need & K & $95 \% \mathrm{Cl}$ & Significance \\
\hline Relationships & 0.741 & 0.486 to 0.996 & $0.000^{* *}$ \\
\hline Activities & 0.302 & 0.006 to 0.598 & $0.008^{*}$ \\
\hline Mobility & 0.643 & 0.018 to 1.268 & $0.001^{*}$ \\
\hline Emotional well-being $^{a}$ & - & - & - \\
\hline Physical well-being & 0.348 & 0.158 to 0.538 & $0.002^{*}$ \\
\hline Medication and treatment ${ }^{\mathrm{a}}$ & - & - & - \\
\hline Other issues & 0.648 & 0.360 to 0.936 & $0.000^{* *}$ \\
\hline Discharge planning & 0.706 & 0.343 to 1.069 & $0.004^{*}$ \\
\hline
\end{tabular}

${ }^{*} \mathrm{p}<0.05 ;{ }^{* *} \mathrm{p}<0.001$.

a Unable to compute Cohen's kappa as one variable was a constant 


\section{Discussion}

\section{Summary of findings}

A total of 150 OHSCAPs (assessments and care plans) were audited (68\%). The results of the audit strongly suggest that OHSCAP was not implemented as intended. Considerable variability in the way in which the OHSCAP had been delivered was identified. Assessments were of a reasonable standard, but generally took place later than the target of 7-14 days after arrival; sometimes it took almost two months for the initial assessment. Any needs identified were not consistently translated into care plan actions. There was little evidence to suggest that prisoners had been involved in the care planning process, although this may reflect issues with documentation rather than actual lack of involvement per se. Where reviews were set, they were often not completed, or at least not documented. Therefore, the success of planned actions in addressing needs was unclear. All of these deviations from the training and the OHSCAP manual are likely to have negatively affected the potential of the OHSCAP to have an impact on unmet needs.

Clear differences in the delivery of the OHSCAP were found relating to the core role of the facilitator. Health-care staff addressed a much greater proportion of the needs they identified through subsequent care planning than did prison officers. There were clear difficulties in collaborative working between disciplines in prison. All facilitators had difficulty sharing documentation across the various information systems in use. Additionally, difficulties in resolving issues that did not fall within the remit of their everyday role were evident. Health-care staff made mostly health-care referrals to resolve healthcare needs, and this trend was true, in reverse, for the prison officer facilitators. Overall, very few referrals to external agencies were made. This apparent inability to share information and successfully collaborate with partner agencies within, and outside, the prison was likely to have been a major barrier to the successful implementation of the OHSCAP.

\section{Strengths and limitations}

Just over two-thirds (68\%) of the completed OHSCAPs were available for audit. All of one site's assessments were lost entirely, reportedly because documents were destroyed as part of the process of changing health-care provider. In another site, only $2 \%$ of documents were recoverable for audit.

Despite the original protocol specifying that $10 \%$ of the OHSCAPs should be reviewed, it was decided to review $100 \%$ of the audits. This decision was made because the number of sites involved in the RCT increased from 4 to 10 and this would ensure a clearer understanding of how well OHSCAPs were completed at each site. The auditor was trained by the research team and was independent of the trial. Some sections of the bespoke audit tool required 
a subjective judgment to be made, which could have impacted on reliability. However, $10 \%$ of the OHSCAPs were also reviewed by one of the researchers employed on the RCT, with good agreement between raters. Regardless of which or how many individuals were involved in the audit process, the audits were based on the actual documented comments within the OHSCAP plans. Without being present for the assessment interview, it is not possible to know to what extent what happened in practice was fully reflected in the documentation.

\section{Implications}

When exploring difficulties in implementation of the OHSCAP the lack of evidence of prisoner involvement is of concern. Shared goals and values, and engagement at all levels is crucial in successfully implementing interventions (Pearson et al., 2015) and needs to be considered in future interventions, both in research and clinical practice. This is likely to have been compounded by the lack of collaborative working between disciplines in prison. Improving collaborative working with formal agreements regarding information sharing and respective roles and responsibilities can increase the success of interventions (Pearson et al., 2015).

It is of critical importance to ensure that complex interventions such as this are embedded effectively at the initial stage, and to ensure that this continues to be the case as the intervention proceeds. Throughout the study, two training sessions were held at the University of Manchester, which were attended by facilitators from all study sites. Some of the facilitators attended both sessions and were able to share experiences and good practice, having already completed the OHSCAP process with some prisoner participants. Ongoing support was also offered by a clinician with vast experience within prison settings who acted as a mentor to facilitators and was contactable by telephone and e-mail, should they have any questions or need any reassurance. Additional site-specific training sessions were provided at prisons that joined part-way through the study in an attempt to bolster recruitment. Regular review and audit of the fidelity of implementation of interventions, with input where required, has been shown to improve the quality and rates of completion of assessments within prison (Grubin et al., 1999). A similar approach with regular checking of care plans and input to prevent slippage of delivery may have improved the implementation of the OHSCAP in this study.

Differences in care planning relating to facilitator role merit further consideration of the perceived role of prison officers. Differing understanding and skills regarding mental health problems, along with tensions between treatment and custody models, is a common difficulty in the implementation of interventions such as this in a prison environment (Pearson et al., 2015). Given that the OHSCAP is a health and social care planning tool, it may be 
that the health-care staff were better placed to address the majority of the issues raised. The closest comparative process to the OHSCAP undertaken by prison officers is the ACCT process for those identified as at risk of self-harm and/or suicide. Similar failings have been found in regard to incomplete and inadequate care planning and a lack of robust review and follow-up processes within that system (Corston, 2007). This may reflect a fundamental issue around the prison officer role not always naturally or universally adapting to an overt caring function as required by the ACCT and the OHSCAP. Furthermore, both ACCT and OHSCAP reviews are designed to be conducted at intervals that are appropriate to individuals' needs, rather than at set intervals. Evidence suggests that prison staff find making decisions about when to conduct the ACCT reviews reactive to need rather than to a set timetable to be difficult; this appears to also be the case with the OHSCAP (Walker et al., 2017). A further problem which is likely to impact on the OHSCAP is the relative importance accorded to the needs of older prisoners, when compared with the prominence of suicide prevention in the media, and in terms of national policy and targeted implementation.

Early days and weeks in custody are difficult, and prisoners are at a high risk of suicide. The delay in conducting the OHSCAP means that important health, social and care needs and risks, with consequent action regarding care pathways, medication and referrals, may be missed. Evidence indicates that if not picked up early, such needs often remain unaddressed throughout their entire sentence (Crawley, 2005). A review of early custody induction processes is required to ensure early identification of needs and appropriate intervention.

The current study was conceived and in process at a time when the coalition government introduced policies with the intention of reducing the full-time equivalence of staff across NOMS as a whole to reduce costs; significant numbers of operational prison officers were reduced as a result. The audit revealed the apparent lack of individual engagement with prisoners during the OHSCAP process. Under previous models of custody, prison officers were named as personal officers for a small number of prisoners in their residential location, with the aim of allowing them to build constructive relationships designed to support prisoners in a range of aspects of their imprisonment, including desistance from crime, maintaining family contact, skills and vocational activity, and discharge planning. Such relationships can facilitate both the addressing of individual needs of prisoners and involve them meaningfully in planning their own care. Engaging people in planning their own care needs and setting individual goals is of critical importance in the success of any intervention within prisons (Pearson et al., 2015).

Echoing the audit findings, HMCIP (HMCIP, 2016) reported evidence of there being less time for meaningful interaction and, therefore, little action taken in response to prisoners' complaints or requests for help. In addition, 
they found that previous progress made in terms of addressing equality and diversity issues had been undone as a result of cutbacks to resources. Of particular concern in our study was the finding that areas of need that the Ministry of Justice (Ministry of Justice, 2016b) and others (Cornish et al., 2016; Forsyth et al., 2014) have highlighted as key to reducing reoffending and ensuring the resettlement of prisoners into the community post release were the needs least often addressed by OHSCAP facilitators. For example, longstanding needs, in relation to discharge planning, emotional well-being and family relationships, were rarely actioned in subsequent care plans.

The House of Commons Justice Select Committee has stipulated that:

'The key explanatory factor for the obvious deterioration in standards over the last year is that a significant number of prisons have been operating at staffing levels below what is necessary to maintain reasonable, safe and rehabilitative regimes.' (House of Commons, 2015).

This loss of prison officer numbers has been linked, by a range of media, political and societal informants, to a range of complex and inter-related negative outcomes with significant increases in self-inflicted deaths, self-harm incidents and violence from 2015 to 2016 [Prison Reform 35]. More recently, there has been a welcome fall in self-inflicted deaths, but self-harm and violence towards both prisoners and staff continue to rise. It is hoped that the roll out of the new Offender Management in Custody (OMiC) model will have a positive impact. This aims to increase staffing levels on residential units and provide an officer 'key worker' for every prisoner (HMPPS, 2018). However, there has been a significant increase in resignations amongst prison officers in recent years (Bulman, 2019) and it should be acknowledged that the recruitment of a relatively small (in comparison with the overall reduction in the prison officer workforce since 2010) number of new recruits will, arguably, not compensate for the prison officers with considerable experience who have been lost since 2013.

\section{Disclosure statement}

No potential conflict of interest was reported by the author(s).

\section{Funding}

This project was funded by the National Institute for Health Research (NIHR) Health Services and Delivery Research programme.

\section{ORCID}

Nicola Swinson (D) http://orcid.org/0000-0002-8305-341X

Jane Senior (D) http://orcid.org/0000-0002-7133-4898 


\section{References}

Altman, D. (1991). Practical Statistics for Medical Research. Chapman \& Hall.

AmericanCivilLiberties Union. (2012). At America's expense: the mass incarceration of the elderly. Available from: www.aclu.org/criminal-law-reform/report-americasexpense-mass-incarceration-elderly

Bridgewood, A., \& Malbon, G. (1995). Survey of Physical Health Needs of Prisoners. O.f.N. Statistics. Editor.

Bulman, M. (2019). In the independent 2018. https://www.independent.co.uk/news/ uk/home-news/number-of-prison-officers-resigning-from-post-soars-amid-soaringlevels-of-violence-and-selfharm-a8427616.html

Cornish, N., Edgar, K., Hewson, A., \& Ware, S. (2016). Social Care or Systematic Neglect? Older People on Release from Prison. Prison Reform Trust and Restore Support Network.

Corston, J.(2007). The Corston Report: A Review of Women with Particular Vulnerabilities in the Criminal Justice System. Home Office.

Crawley, E. (2005). Institutional thoughtlessness in prisons and its impacts on the day-to-Day prison lives of elderly men. Journal of Contemporary Criminal Justice, 21(4), 350-363. https://doi.org/10.1177/1043986205282018

Davies, M. (2011). The reintegration of elderly prisoners: An exploration of services provided in England and Wales. Internet J Criminol, 1, 1-32.

Fazel, S., Hope, T., O'Donnell, I., \& Jacoby, R. (2001). Hidden psychiatric morbidity in elderly prisoners. The British Journal of Psychiatry: The Journal of Mental Science, 179 (6), 535-539. https://doi.org/10.1192/bjp.179.6.535

Fazel, S., Hope, T., O'Donnell, I., \& Jacoby, R. (2004). Unmet treatment needs of older prisoners: A primary care survey. Age and Ageing, 33(4), 396-398. https://doi.org/10. 1093/ageing/afh113

Forsyth, K. (2017, December). The effectiveness of the Older prisoner Health and Social Care Assessment and Plan (OHSCAP): A randomised controlled trial. NIHR Journals Library.

Forsyth, K., Senior, J., Stevenson, C., O'Hara, K., Hayes, A., Challis, D., \& Shaw, J. (2014). 'They just throw you out': release planning for older prisoners. Ageing and Society, 35(9), 2011-2025. https://doi.org/10.1017/S0144686X14000774

Frazer, L. (2003). Ageing Inside., in School for Policy Studies Working Paper Series. Bristol: University of Bristol.

Ginn, S. (2012). Elderly prisoners. BMJ, 345(oct15 4), e6263. https://doi.org/10.1136/ bmj.e6263

Grubin, D., Parsons, S., \& Hopkins, C. (1999). Report on the evaluation of a new reception health questionnaire and associated training. London: HM Prison Service.

Hayes, A. J. (1999). Joint Prison Service and National Health Service Executive Working Group., The Future Organisation of Prison Health Care., Editor. London: D.o. Health. Accessed 19 October 2013. http://webarchive.nationalarchives.gov.uk/ 20110504020423/http://www.dh.gov.uk/prod_consum_dh/groups/dh_digitalas sets/@dh/@en/documents/digitalasset/dh_4106031.pdf

Hayes, A. J., Burns, A., Turnbull, P., and Shaw, J. J. (2012). The health and social needs of older male prisoners. International Journal of Geriatric Psychiatry, 27(11), 1155-1162. https://doi.org/10.1002/gps.3761

Hayes, A. J., Burns, A., Turnbull, P., \& Shaw, J. J. (2013). Social and custodial needs of older adults in prison. Age and Ageing, 42(5), 589-593. https://doi.org/10.1093/ ageing/aft066 
HM Inspectorate of Prisons. (2008). Older Prisoners in England and Wales: A Follow-up to the 2004 Thematic Review by HM Chief Inspector of Prisons. London: HM Inspectorate of Prisons.

HMCIP. (2016). HM Chief Inspector of Prisons for England and Wales Annual Report 2015-16.

HMPPS. (2018). Her Majesty's Prison and Probation Service Annual Report and Accounts 2017-18.

House of Commons. (2015). Prisoners: Planning and Policies Ninth Report of Session 2014-15. Justice. Committee. Editor.

Howse, K. (2003). Growing Old in Prison. A Scoping Study on Older Prisoners. Prison Reform Trust.

Kingston, P., Le Mesurier, N., Yorston, G., Wardle, S., \& Heath, L. (2011). Psychiatric morbidity in older prisoners: Unrecognized and undertreated. International Psychogeriatrics / IPA, 23(8), 1354-1360. https://doi.org/10.1017/ S1041610211000378

Ministry of Justice. (2014). Offender Management Caseload Statistics 2013. M.o. Justice. Editor.

Ministry of Justice. (2016a). Offender Management Statistics Bulletin, England and Wales.

Ministry of Justice. (2016b). Prison Safety and Reform.

Ministry of Justice. (2004). White Paper On Crime 2004: Treatment of Offenders. 2004.

Pearson, M., Brand, S. L., Quinn, C., Shaw, J., Maguire, M., Michie, M., \& Byng, R. (2015). Using realist review to inform intervention development: Methodological illustration and conceptual platform for collaborative care in offender mental health. Implementation Science, 10(1), 134. https://doi.org/10.1186/s13012-015-0321-2

Prior, G. (1998). Self Reported Health. HMSO.

Senior, J., O'Hara, K., Forsyth, K., Walsh, E., Stevenson, C., \& Shaw, J. (2013). Health and social care services for older male adults in prison: The identification of current service provision and piloting of an assessment and care planning model. Queen's Printer and Controller of HMSO 2013.

Shaw, J., Senior, J., Hassan, L., King, C., Mwasambili, N., \& Lennox, C. (2009). An Evaluation of the Reception Health Screening Process Used Within Prisons in England and Wales. University of Manchester.

Wahidin, A. (2005). Ageing, Crime and Society. Oxford University Press.

Walker, T., Shaw, J., Turpin, C, Reid, C., \& Abel, K. (2017). The WORSHIP II study: A pilot of psychodynamic interpersonal therapy with women offenders who self-harm. The Journal of Forensic Psychiatry \& Psychology, 28(2), 158-171. https://doi.org/10.1080/ 14789949.2017.1301529

Williams, B. A., Lindquist, K., Sudore, R. L., Strupp, H. M., Willmott, D. J., \& Walter, L. C. (2006). Being old and doing time: Functional impairment and adverse experiences of geriatric female prisoners. Journal of the American Geriatrics Society, 54(4), 702-707. https://doi.org/10.1111/j.1532-5415.2006.00662.x 